\title{
Indirect comparison of etanercept and abatacept efficacy and safety in patients with polyarticular juvenile idiopathic arthritis
}

\author{
OU Loskutova (Konopelko)", ES Zholobova, MN Nikolaeva, LA Galstian \\ From 21st European Pediatric Rheumatology (PReS) Congress \\ Belgrade, Serbia. 17-21 September 2014
}

\section{Introduction}

The use of biological DMARDs have significantly improved the prognosis and prospects for patients with juvenile idiopathic arthritis (JIA). Today the main problem for pediatric rheumatologists when choosing JIA treatment is the absence of comparative controlled studies of efficacy and safety of different biological DMARD.

\section{Objectives}

To compare efficacy and safety of etanercept and abatacept in pediatric patients with polyarticular JIA.

\section{Methods}

The study enrolled 54 pediatric patients with polyarticular JIA, 32 of them received etanercept and 22 received abatacept. The demographic parameters were well matched across treatment groups. The mean age of children was $10.8 \pm 3.7$, the age at the disease onset was $5.4 \pm 3.4$, most of the patients were female. Prior to biological DMARD administration, all the subjects received multiple basic immunosuppressants. A total of $68,7 \%$ of subjects in the etanercept arm had disease activity grade II before biological DMARD administration, $31.3 \%$ had grade III; $54.6 \%$ of subjects in the abatacept arm had disease activity grade I, $31.8 \%$ grade II, and $13.6 \%$ grade III. American College of Rheumatology "pediatric" criteria (ACR pedi-30, -50, -70, -90), treatment compliance index and index LUNDEX were used to assess efficacy of the study treatment. Biological DMARD efficacy and safety were evaluated at Months 6, 12, 18 and 24 following therapy initiation. The drugs were given at standard doses.

\section{Results}

At least a $50 \%$ improvement according to ACR pedi was achieved in $84.3 \%$ of etanercept arm subjects and in $71,4 \%$ in patients receiving abatacept following 6 months of treatment. Drug-induced clinical and laboratory remission (ACR pedi 90,100) was achieved in $15.6 \%$ of subjects in the etanercept arm, and in $9.5 \%$ of patients receiving abatacept. After that, biological DMARD efficacy continued to increase. At Month 18, ACR pedi 50 was achieved in $100 \%$ and ACR pedi 90 in $31.0 \%$ of etanercept subjects; ACR pedi 50 was achieved in $83,3 \%$, and ACR pedi 90 in $33.3 \%$ of abatacept subjects. The treatment compliance index at Month 18 was 0,97 in the etanercept arm and 0.8 in the abatacept arm. Index LUNDEX was 0.97 for ACR pedi 50, and 0,3 for ACR pedi 90 in the etanercept arm; in the abatacept arm, it was 0.67 for ACR pedi 50 , and 0.27 for ACR pedi 90. At Month 24 all the patients achieved a $50 \%$ response according to the ACR pedi criteria. Druginduced clinical and laboratory remission was achieved in $43.0 \%$ of subjects in the etanercept arm, and in $67 \%$ of subjects in the abatacept arm. A greater treatment compliance index was obtained in the etanercept arm ( 0.94 versus 0.6 in the abatacept arm). Thus, when biological DMARD efficacy is compared using index LUNDEX to ACR pedi 50, the best result was obtained with etanercept when compared to abatacept, the values were 0,94 and 0,6 , respectively. Index LUNDEX to ACR pedi 90, 100 was 0,4 in both arms. The difference between biological DMARD efficacy was not significant $(\mathrm{p}<0,05)$. Adverse drug reactions were more frequent in the abatacept arm $(22.7 \%)$ than in the etanercept arm (12.5\%). Serious adverse reactions were also more frequent with abatacept treatment (9\%) than with etanercept (3\%; $>0.05)$. 


\section{Conclusion}

Etanercept and abatacept are highly effective drugs for pediatric treatment of polyarticular JIA. Etanercept has a better safety profile than abatacept.

\section{Disclosure of interest}

None declared.

Published: 17 September 2014

doi:10.1186/1546-0096-12-S1-P132

Cite this article as: Loskutova (Konopelko) et al:: Indirect comparison of

etanercept and abatacept efficacy and safety in patients with polyarticular

juvenile idiopathic arthritis. Pediatric Rheumatology 2014 12(Suppl 1):P132.

Submit your next manuscript to BioMed Central and take full advantage of:

- Convenient online submission

- Thorough peer review

- No space constraints or color figure charges

- Immediate publication on acceptance

- Inclusion in PubMed, CAS, Scopus and Google Scholar

- Research which is freely available for redistribution

Submit your manuscript at www.biomedcentral.com/submit 